\title{
Outlook brightens for science in US budget proposals for 1998
}

[WASHINGTON] President Bill Clinton has proposed increases close to the rate of inflation for most US science agencies in his 1998 budget, lifting a threat that his plans to balance the overall federal budget by 2002 would severely hit research funding.

The budget plan for the next financial year, which begins in October, would increase total federal spending on research and development (R\&D) by 2 per cent, to $\$ 75.5$ billion. Non-defence R\&D would grow by 4 per cent to $\$ 35$ billion. The proposal will now be considered by the Congress, which is due to pass final budget bills by 1 October.

Advocates for science gave the budget a cautious welcome, pointing out that the spending proposed for 1998 comfortably exceeds that projected by the administration 12 months ago. And new projections to 2002 remove the threat of sharp cuts at the National Aeronautics and Space Administration (NASA), the National Science Foundation (NSF) and the Department of Energy.

"Given the tenor of the times, this is quite an optimistic budget," says Cornelius Pings, president of the Association of American Universities. Pings says that the budget proposals suggest that "the concerted efforts of the science community to engage the administration are perhaps beginning to pay off".

At the same time, there was criticism of the president for failing to assure real growth in the 1998 budgets of the NSF and the National Institutes of Health, the two agencies that fund most university science.

\section{IMAGE \\ UNAVAILABLE FOR COPYRIGHT REASONS}

Clinton: proposals would avoid major cuts but do not guarantee growth for NSF and NIH.

But Jack Gibbons, Clinton's science adviser, said that, although there had been widespread concern that balancing the budget might require cuts of a quarter or one-third in research, "we've been working to make sure that does not come to pass".

Under the new projections, non-defence R\&D would grow by 2 per cent between 1998 and 2002. But Gibbons stressed that research agencies might choose to fight to win larger increases than that.

Al Teich, head of science policy research at the American Association for the Advancement of Science, says that a combination of the revised projections and lower inflation - down to 2.2 per cent - is likely to ease the pressure on science funding.

In 1998, the administration proposes more funds for civilian technology programmes, including the Advanced Tech-
\& nology Program (up 22 per cent to $\$ 275$ million) and the dual-use programme at the Department of Defense (up 24 per cent to $\$ 225$ million). But these increases are less aggressive than those sought for technology programmes in previous Clinton budgets.

George Brown (Democrat, California), the senior Democrat on the science committee in the House of Representatives, said that Clinton's budget "falls far short of what needs to be done". Brown has produced his own "investment budget" which funds more science and education by cutting military spending. But he welcomed "the improved long-term outlook for agencies such as NASA" in the budget projections for the years beyond 1998 .

Republican reaction to Clinton's budget proposal was muted, with congressional leaders leaving Washington the day after the budget for a weekend retreat to consider their strategy.

Science lobbyists detect growing signs that the Republican leadership will back funding increases for research. For instance, Senator Trent Lott (Republican, Mississippi), Senate majority leader, has called for more Department of Defense support for universities. In a letter to Ted Stevens (Republican, Alaska), the chair of the Senate appropriations committee, Lott praised the universities' role in national defence and attacked "the eroding commitment to research" by the department.

Colin Macilwain

For full budget details, see pages 568 and 569

\section{Japanese increases include support for CERN's Large Hadron Collider}

[TOKYO] Japan has increased its

financial support for the Large Hadron Collider being built at the European Laboratory for Particle Physics (CERN) in Geneva,

Switzerland, in a supplementary budget aimed at reinvigorating the flagging Japanese economy.

The Ministry of Education, Science, Sports and Culture will receive $¥ 3.85$ billion (US $\$ 31$ million) for collider construction in a supplementary budget for fiscal year 1996, which ends on 31 March, passed by Japan's parliament, the Diet, at the end of last month. This comes on top of $¥ 5$ billion given to the project in a supplementary budget in 1995 .

The past few years have seen a string of supplementary budgets, intended mainly to help pull Japan out of recession. But each has also contained substantial outlays for science and technology.

The present supplementary budget, at $¥ 2,666$ billion, is small compared to its predecessors, some of which exceeded $¥ 10,000$ billion. But, as anticipated after the Liberal Democratic party regained power in October (see Nature 383 , $750 ; 1996)$, the outlays for science and technology are comparatively large, at $¥ 155$ billion. This will add 5 to 10 per cent to the rapidly increasing budgets of sciencerelated ministries and agencies.

Key beneficiaries will be Japan's universities, including the national research institutes used by several universities, such as the high-energy physics laboratory at Tsukuba science city and the Institute of Space and Astronautical Science.

Japan's contribution to the international space station goes up by $¥ 7$ billion, and there is $¥ 5.6$ billion for SPring-8, the world's most powerful synchrotron. Another $¥ 3$ billion will be spent on Mirai, the giant oceanographic vessel made by converting the illfated nuclear-powered ship Mutsu to diesel-electric power.

The Ministry of International Trade and Industry (MIT) will use its supplementary budget of $¥ 33$. 2 billion to improve facilities at the research institutes of its Agency of Industrial Science and
Technology.computer networks.

Another $¥ 2$ billion will be spent on a system to monitor geological faults in the region affected by the Kobe earthquake. The Science and Technology Agency receives a similar amount to set up stations to monitor microearthquakes.

Chris Llewellyn Smith, the director general of CERN, said that he was "delighted" by the LHC decision. "The generous contributions of Japan, with those of other non-member states particularly the United States - will enable the LHC to be built in a single stage and represent an important step forward in interregional scientific collaboration," he said.

Richard Nathan \& David Swinbanks 